\title{
Association Between Perinatal Medical Expenses and a Waiver to Increase Florida Healthy Start Services Within Florida Medicaid Programs: 1998 to 2006
}

\author{
Stephanie A. S. Staras • John A. Kairalla $\cdot$ Wei Hou • \\ William M. Sappenfield • Daniel R. Thompson • \\ Deepa Ranka • Elizabeth A. Shenkman
}

Published online: 11 May 2011

(C) The Author(s) 2011. This article is published with open access at Springerlink.com

\begin{abstract}
To assess the association between perinatal care expenditures and a Medicaid waiver to increase Florida Healthy Start services among Florida Medicaid non-managed care organization (non-MCO) program enrollees. We assessed perinatal care expenditures from Medicaid claims and encounter data among non-MCO enrollees with increased risk pregnancies who gave birth in Florida during 1998-2006. We used a pre-post design to compare adjusted perinatal medical expenditures among women who received Healthy Start care coordination $(\mathrm{n}=41,067)$ to women who were not contacted by the Healthy Start program after screening $(n=24,282)$. We calculated adjusted average costs and difference-in-differences using marginal estimates from multivariable linear mixed regression models. From the pre-waiver (January 1998-July 2001) to the late-post waiver (July 2004December 2006), all prenatal medical costs increased $\$ 274$ among care coordination participants and decreased $\$ 601$ among women not contacted by the Healthy Start program, equaling a $\$ 875$ increased cost difference between care coordination and no contact groups. During this same time period, delivery related expenditures increased \$395 less
\end{abstract}

S. A. S. Staras $(\bowtie) \cdot$ D. Ranka · E. A. Shenkman

Department of Health Outcomes and Policy, College

of Medicine, and the Institute for Child Health Policy,

University of Florida, 1329 SW 16th Street, Room 5241,

Gainesville, FL 32610, USA

e-mail: sstaras@ufl.edu

J. A. Kairalla · W. Hou

Department of Biostatistics, University of Florida,

Gainesville, FL, USA

W. M. Sappenfield · D. R. Thompson

Division of Family Health Services, Florida Department

of Health, Tallahassee, FL, USA among care coordination participants compared to women not contacted by Healthy Start. Additionally, infant medical care costs during days 29-365 decreased by an average of \$240 less among the care coordination compared to the no contact group. The Medicaid waiver may have decreased delivery costs, but medical costs were increased following the waiver when considering all perinatal care. Further exploration of factors associated with the decreased delivery costs may help develop more efficient prenatal support programs.

Keywords Prenatal care $\cdot$ Perinatal care medical expenses $\cdot$ Medicaid $\cdot$ Florida Healthy Start

\section{Introduction}

In the United States, approximately $12 \%$ of children are born before 37 completed weeks of gestation (preterm) and $6 \%$ are born weighing less than 2,500 grams (low birth weight) [1]. During the past 20 years, national rates of low birth weight and preterm births have increased by approximately $10 \%$ [1]. Children born preterm or low birth weight are at increased risk of morbidity and mortality throughout childhood [2-7]. Adjusted to 2008 dollars [8], estimated annual medical expenditures are $\$ 30.8$ billion for preterm births and \$14-\$16 billion for low birth weight infants $[9,10]$.

The Healthy Start initiative consists of federal and state supported programs focused on using care coordinators to connect women with prenatal care and additional services (e.g., transportation or tobacco cessation) [11]. Most evaluations of Healthy Start and other case management programs find little effect of these types of programs on birth outcomes [12-15]. But, a few studies 
have found improved birth outcomes among participants of Healthy Start or other case management programs [1618]. Most studies did not evaluate medical expenditures [19], but the few that did found reduced medical costs for delivery and infant care in the first 60 days among case management participants compared to non-participants $[17,18]$.

In Florida, in addition to the six federally funded sites, the state supports a Florida Healthy Start program focused on providing prenatal care, infant care, and additional services statewide. In July 2001, Florida Healthy Start services were included as Medicaid reimbursable costs with a Medicaid 1915(b)(1) waiver [20]. The long-term goal of the Medicaid waiver was to reduce poor birth outcomes, and consequently, reduce medical expenditures within Medicaid. Our research objective was to determine whether including Healthy Start services as Medicaid reimbursable costs was associated with reduced perinatal expenditures among women at increased risk of poor birth outcomes enrolled in Florida Medicaid non-managed care organization (nonMCO) programs.

\section{Methods}

\section{Florida Healthy Start Background}

Florida law requires physicians to offer all pregnant women the Healthy Start Screening, a tool designed to measure a woman's risk for poor perinatal outcomes by assessing nutrition, psychosocial health, drug and alcohol use, and domestic stability [21]. Screen scores of $\geq 4$ suggest an increased risk of poor perinatal outcomes, and qualify women for referral to the Healthy Start program. Additionally, health care providers may refer women to the Healthy Start program regardless of their completion of or score on the screening.

Women referred to Florida Healthy Start are contacted by one of the Florida Healthy Start coalitions (communitybased non-profit agencies coordinating the program) or one of the county health departments. If the woman can be contacted and agrees to participate, a care coordinator evaluates her risk factors and assets. Based on this initial assessment, four possible determinations can be made: (1) no need for services, (2) tracking of risk factors throughout pregnancy, (3) providing select Healthy Start services, and (4) providing ongoing care coordination. Women referred to care coordination are assigned a coordinator who works with the families throughout pregnancy to select and facilitate delivery of services including transportation assistance, parenting education, and smoking cessation counseling [22].
Study Design

We used a pre-post design with an intervention group and a comparison group to evaluate the economic influence of the waiver. We defined four time periods of study: (1) a pre-waiver period from January 1, 1998 to July 1, 2001; (2) a transition period to encompass waiver roll-out from July 2, 2001 to March 23, 2002; (3) an early post-waver period to reflect initial program experiences from March 24, 2002 through July 1, 2004; and (4) a late post waiver period to reflect experiences with a more mature program from July 2, 2004 through December 31, 2006. For simplicity, and because the transition period is a short time period representing a mix of waiver implementation, results for the transition period are not presented. The Institutional Review Board at the University of Florida approved the study protocol.

\section{Study Population}

Using Florida birth and fetal death certificates, we identified women giving birth between January 1, 1998 and December 31, 2006. We limited the study to 349,554 births for whom we could link: (1) the child's birth certificate or fetal death record; (2) the mother's Healthy Start screen and services file, (3) the mother's Medicaid enrollment and claims and encounter data, and (4) the child's Medicaid enrollment and claims and encounter data. We could not include births to mothers in Medicaid MCO programs $(\mathrm{n}=56,632)$ because we could not assess expenditures since the State did not collect itemized claims and encounter data for Medicaid MCO programs until 2009. Thus, both the mother and child must have been enrolled in Florida Medicaid non-MCO programs to be included in our analysis.

We restricted our focus to women at increased risk of poor birth outcomes, defined as births to women eligible for risk assessment based on their Healthy Start screen score of $\geq 4(n=111,476)$ (Fig. 1). To limit the influence of very high cost births, we excluded multiple births and births to women eligible for Medicaid based on medical need $(\mathrm{n}=3,334)$. We also excluded enrollees who did not report White, Black, or Hispanic race/ethnicity $(\mathrm{n}=1,973)$ because other racial/ethnic groups were too small to maintain model stability. After removing births missing covariate information, we had data for 102,989 births.

\section{Intervention and Comparison Groups}

The intervention group included births to women who received Healthy Start care coordination $(n=41,067)$. Because of the small sample size $(n=566)$, we were unable to assess costs among births to women who 


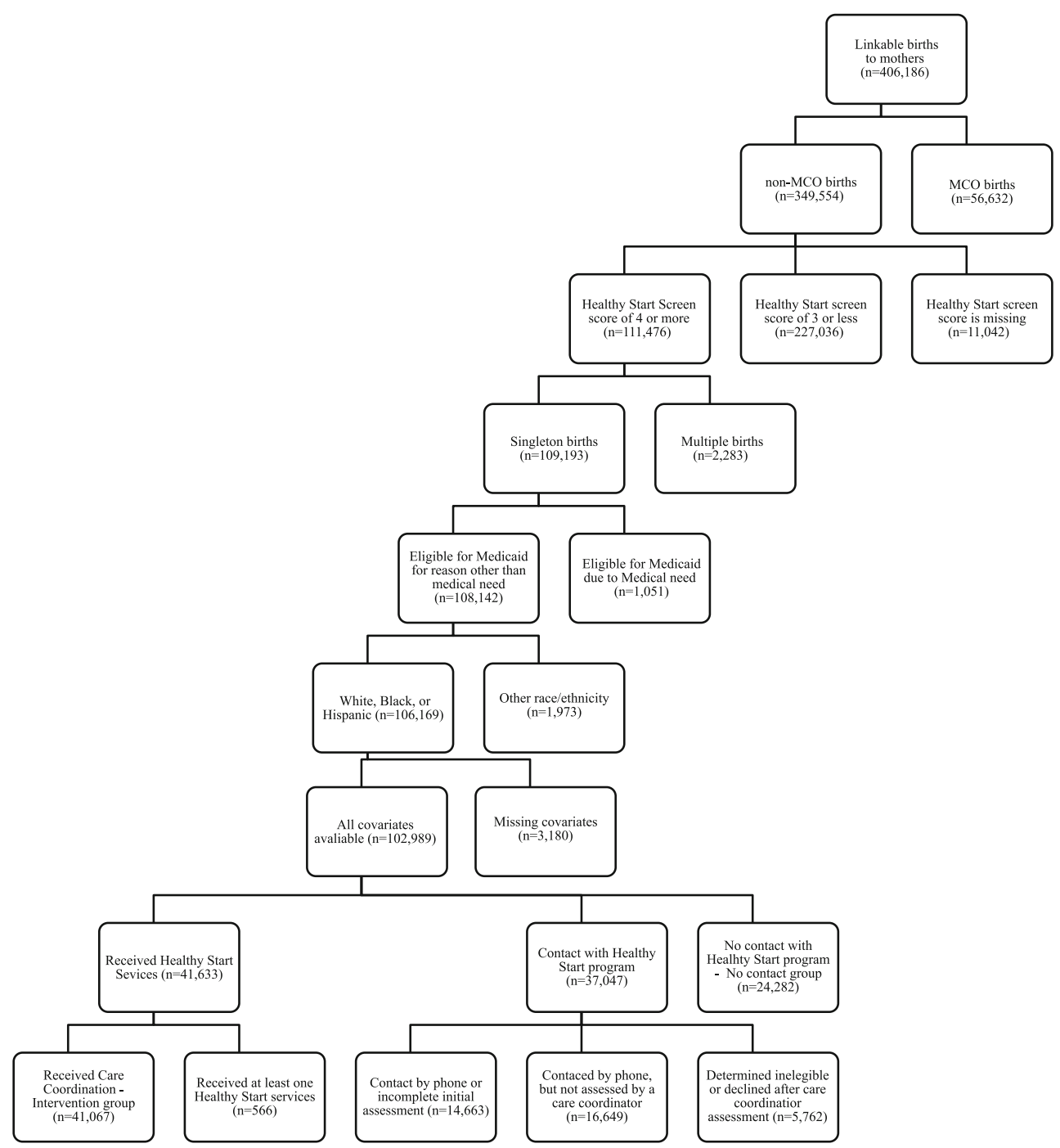

Fig. 1 Selection of care coordination and no contract group from linkable Florida births between 1998 and 2006

received at least one Healthy Start service, but did not receive care coordination.

Because the waiver was implemented statewide in July 2001, a temporal comparison group of women unexposed to the waiver was not available. Therefore, we defined the observational comparison group as births to women who completed the Healthy Start screening form, but did not have further contact with the Healthy Start personnel or services $(n=24,282)$. Thus, these women did not have an opportunity to participate or be evaluated by Healthy Start personnel. Hereafter, the comparison group is referred to as the no contact group.

We excluded births to women who had some contact with the Healthy Start program, but did not receive any services: 14,663 had records of attempts to contact by phone or had an incomplete initial assessment, and 16,649 were contacted by phone, but not assessed by a care coordinator. We also excluded births to women who were determined ineligible or declined after care coordinator assessment, because these women likely have more resources and less need for services $(n=5,762)$.

\section{Economic Outcome Measures}

Using the paid amounts in the Medicaid claims and encounter data, we assessed eight measures of medical expenditures associated with the perinatal period. Because the study period spans 9 years and medical expenditures increase each year, all expenditures were adjusted for inflation with the urban medical care consumer price index to 2008 dollars [8].

Prenatal and postpartum visits were restricted to claims meeting the prenatal and postpartum definitions suggested by the Health Employer Data and Information Set (HEDIS) technical specifications [23]. We estimated the prenatal period by subtracting the number of gestation weeks 
(clinical estimate on birth certificate) from the date of birth. Prenatal period expenditures assessed were: (1) medical claims during the prenatal period; (2) claims for prenatal care visits; and (3) only claims for prenatal visits considered early by HEDIS, i.e., within the first 42 days of Medicaid enrollment or during the first trimester [23]. Postpartum period expenditures were assessed for the mother during the 8 weeks following delivery, and included (1) all medical claims during the period, and (2) claims for postpartum visits [23].

There was not a reliable strategy to separate mother and child expenditures for claims during the days prior to the mother leaving the hospital following delivery, because infant claims are billed under the mother's Medicaid identification number until the mother leaves the hospital. Therefore, postpartum total medical expenditures may include newborn expenditures, and some infant claims will not be included in the first few weeks following birth. Thus, to account for the different certainty in completeness of the claims data, and the high cost of poor perinatal outcomes during the neonatal period [9], we assessed infant expenditures during two time periods: 2-28 days and 29-365 days.

\section{Covariates}

Based on risk factors in the literature for increased medical costs related to high-risk pregnancies or poor birth outcomes $[1,24,25]$, we selected twelve covariates from the available data. From Medicaid enrollment files, we collected mother's age at child's birth and mother's race/ethnicity. From birth certificate files, we collected: (1) mother's highest education level achieved; (2) mother's marital status; (3) mother's county of residence; (4) estimated gestation weeks calculated from the mother's last menstrual period (when estimated gestation age was not available, we used the clinical estimate of gestation age $(n=7,136))$; and (5) infant's birth weight. From the Healthy Start services file, we obtained the women's screening score. From the Medicaid claims and encounter data, we calculated: (1) timely initiation of prenatal care (using the HEDIS definition of during first trimester or first 42 days enrolled in Medicaid [23]); (2) receipt of postpartum care defined by HEDIS [23]; (3) Mother Chronic Illness and Disability Payment System health score [25]; and (4) the number of pregnancy complications measured by a score of $0-9$ with 1 point assigned for each of nine ICD-9 codes, 640-643 and 645-649 (includes hemorrhage, hypertension, infections, and other conditions complicating pregnancy).

\section{Statistical Analysis}

We estimated expenditures for each time period using marginal means from a multivariable mixed model adjusted for the covariates described previously. Using these adjusted expenditure estimates, we calculated and tested within period differences between care coordination and no contact groups, pre- to post-waiver differences within each group, and difference-in-difference estimates comparing the pre- to post-waiver differences between groups. All analyses were performed using SAS (Cary, NC) version 9.2.

A mixed model analysis was used to account for the correlation between births to the same mother, because about $6 \%$ of women had more than one birth during the 9-year time period (accounting for $11 \%$ of study births). Expenditure outliers were retained in the analyses. Because health care expenditures can be highly skewed, we used a log-transformation to convert the dollar amounts into log amounts to approximate a normal distribution for analysis. To facilitate interpretation, we used Duan's smearing retransformation to convert the log amounts back to dollar amounts [26].

\section{Results}

Distributions of characteristics were relatively stable throughout the 9 years of the study; therefore, overall distributions are presented for simplicity (Table 1). Chisquare tests of the differences between the women receiving care coordination and no contact are significant at the 0.05 level for eight of eleven characteristics; due to the large sample sizes, however, these tests may not represent clinical differences. For example, we would have a $90 \%$ chance of detecting a difference between group frequencies of $15 \%$ and $16 \%$. Women receiving care coordination were more likely than non-contacted women to be non-Hispanic White, have a Healthy Start screen score higher than four, receive timely prenatal care, and have at least one maternal complication. We control for the small differences between group characteristics (Table 1), as well as mother's county of residence, through multivariable adjustment of all expenditure estimates.

\section{Prenatal Period Expenditures}

Within all time periods studied, average medical expenditures during the prenatal period were between $\$ 319.92$ and $\$ 1,245.29$ higher among care coordination participants than among the no contact group (Table 2). Compared to the pre-waiver period, adjusted average medical costs increased among the care coordination group: increase of $\$ 484.35$ by the early post-waiver and $\$ 274.08$ by the latepost waiver (Table 2). In contrast, medical costs among the no contact group decreased following the waiver: decrease of $\$ 441.03$ by early post-waiver and $\$ 601.02$ by the late 
Table 1 Characteristics for study population from 1998 to 2006 by intervention subgroup

\begin{tabular}{lll}
\hline Care coordination & No contact \\
$\mathrm{N}=41,067$ & $\mathrm{~N}=24,282$ \\
& Percentage & Percentage \\
\hline
\end{tabular}

Mothers' characteristics

Mother's race**

Non-Hispanic White

Non-Hispanic Black

36.0

29.1

Hispanic

53.2

58.9

Mother's age

$11-17$ years

10.9

12.0

$18-20$ years

18.2

16.6

21-35 years

28.9

30.5

$\geq 36$ years

48.3

4.6

48.6

4.3

Mother's education

Less than high schoo

50.4

49.9

High school

35.9

At least some college

13.7

Mother married*

15.1

Mother's Healthy Start screen score**

4

43.2

5

30.1

16.3

6

10.4

7 or more

Received timely prenatal care** 70.6

Mother's CDPS score**

\begin{tabular}{|c|c|c|}
\hline 0 & 3.8 & 5.2 \\
\hline 1 & 60.6 & 63.8 \\
\hline 2 & 24.1 & 21.9 \\
\hline$\geq 3$ & 11.6 & 9.1 \\
\hline \multicolumn{3}{|c|}{ Number of maternal complications** } \\
\hline 0 & 29.2 & 34.8 \\
\hline 1 & 34.8 & 34.9 \\
\hline 2 & 22.7 & 19.7 \\
\hline$\geq 3$ & 13.3 & 10.6 \\
\hline Postpartum care $* *$ & 83.5 & 80.2 \\
\hline \multicolumn{3}{|l|}{ Infants' characteristics } \\
\hline \multicolumn{3}{|l|}{ Gestation weeks** } \\
\hline $\begin{array}{l}\text { Very and moderate } \\
\text { preterm }\end{array}$ & 4.0 & 4.6 \\
\hline Late preterm & 10.6 & 11.1 \\
\hline Term & 76.6 & 76.2 \\
\hline Post term & 8.8 & 8.1 \\
\hline \multicolumn{3}{|l|}{ Birth weight } \\
\hline $\begin{array}{l}\text { Very low } \\
\quad(<1,500 \text { grams })\end{array}$ & 1.7 & 2.0 \\
\hline Low $(1,500-<2,500$ grams $)$ & 9.2 & 9.0 \\
\hline Normal ( $\geq 2,500$ grams $)$ & 89.1 & 89.0 \\
\hline
\end{tabular}

* Chi-square test significant at $P<0.05$

** Chi-square test significant at $P \leq 0.001$ post-wavier. The difference of these changes resulted in increased costs among the care coordination group compared to the no contact group ( $\$ 925.37$ early post-waiver and $\$ 875.10$ late post-waiver).

Similarly, costs for HEDIS prenatal visits were between $\$ 85.16$ and \$200.08 higher among the care coordination group compared to the no contact group within each time period studied (Table 2). Following the waiver, expenditures for HEDIS prenatal visit expenditures decreased within both groups (Table 2); comparing the late postwaiver to the pre-waiver period, prenatal care expenditures were $\$ 181.75$ less among the care coordination group and \$281.77 less among the no contact group. Thus, by late post-waiver, costs among the no contact group decreased $\$ 100.02$ more than the care coordination group. Similarly, by the early post-waiver, costs among the no contact group decreased $\$ 114.92$ more than the care coordination group.

In contrast, early prenatal care expenditures were lower among women receiving care coordination compared to women who were not contacted during all time periods with differences of \$25.71-\$290.99 (Table 2). Between the early post-waiver and pre-waiver periods, early prenatal care costs decreased by $\$ 33.50$ for the care coordination group and increased by $\$ 160.21$ for the no contact group. Thus, the short-term waiver effect suggests an average savings of $\$ 193.67$ following the waiver. But, the longterm waiver effect suggests that the no contact group had increased cost savings compared to the care coordination group for early prenatal care expenditures (Table 2). From the pre-waiver costs to the late post-waiver time period, early prenatal care costs had decreased $\$ 327.81$ for the care coordination group and $\$ 399.43$ for the no contact group.

\section{Delivery and Postpartum Period Expenditures}

In both groups, estimated average delivery expenditures increased from the pre-waiver period to the late postwavier period (Table 3). Delivery related expenditures were consistently lower (range \$93.88-\$488.86) among care coordination participants compared to the no contact group. Delivery expenses increased less among the care coordination group than the no contact group between the pre-waiver and early post-waiver $(\$ 182.33)$, and between the pre-waiver and late post-waiver (\$394.98) (Table 3).

During the pre-waiver period, postpartum visits expenditures were lower among care coordination participants than the no contact group (Table 3). Among both groups, postpartum visit expenditures increased following the waiver. We found little or no evidence of either a short- or long-term waiver effect on postpartum period expenses (Table 3). 
Table 2 Adjusted $^{\mathrm{a}}$ average prenatal care period expenditures and differences between intervention and comparison groups by waiver period

\begin{tabular}{|c|c|c|c|c|c|}
\hline & $\begin{array}{l}\text { Pre-waiver } \\
\text { (Jan. 1, 1998- } \\
\text { July 1, 2001) }\end{array}$ & $\begin{array}{l}\text { Early post-waiver } \\
\text { (March 24, 2002- } \\
\text { July 1, 2004) }\end{array}$ & $\begin{array}{l}\text { Late post-waiver } \\
\text { (July 2, 2004- } \\
\text { December 31, 2006) }\end{array}$ & $\begin{array}{l}\text { Difference Early-post } \\
\text { waiver minus } \\
\text { pre-waiver }\end{array}$ & $\begin{array}{l}\text { Difference Late-post } \\
\text { waiver minus } \\
\text { pre-waiver }\end{array}$ \\
\hline \multicolumn{6}{|l|}{ All medical } \\
\hline Care coordination & $\$ 4,031.05$ & $\$ 4,515.40$ & $\$ 4,305.13$ & $\$ 484.35 * *$ & $\$ 274.08 * *$ \\
\hline No contact & $\$ 3,711.13$ & $\$ 3,270.11$ & $\$ 3,110.11$ & $-\$ 441.03 * *$ & $-\$ 601.02 * *$ \\
\hline Difference $^{\mathrm{b}}$ & $\$ 319.92 * *$ & $\$ 1,245.29 * *$ & $\$ 1,195.02 * *$ & $\$ 925.37 * *$ & $\$ 875.10^{* *}$ \\
\hline \multicolumn{6}{|l|}{ All prenatal visits ${ }^{c}$} \\
\hline Care coordination & $\$ 1,486.34$ & $\$ 1,409.66$ & $\$ 1,304.59$ & $-\$ 76.68 * *$ & $-\$ 181.75^{* *}$ \\
\hline No contact & $\$ 1,401.18$ & $\$ 1,209.59$ & $\$ 1,119.41$ & $-\$ 191.59 * *$ & $-\$ 281.77 * *$ \\
\hline Difference $^{\mathrm{b}}$ & $\$ 85.16^{* *}$ & $\$ 200.08 * *$ & $\$ 185.18 * *$ & $\$ 114.92 * *$ & $\$ 100.02 * *$ \\
\hline \multicolumn{6}{|l|}{ Early prenatal care ${ }^{\mathrm{c}, \mathrm{d}}$} \\
\hline Care coordination & $\$ 836.23$ & $\$ 802.77$ & $\$ 508.41$ & $-\$ 33.50^{*}$ & $-\$ 327.81 * *$ \\
\hline No contact & $\$ 933.56$ & $\$ 1,093.76$ & $\$ 534.12$ & $\$ 160.21 * *$ & $-\$ 399.43 * *$ \\
\hline Difference & $-\$ 97.32 * *$ & $-\$ 290.99 * *$ & $-\$ 25.71 *$ & $-\$ 193.67 * *$ & $\$ 71.61 *$ \\
\hline
\end{tabular}

* Significant at $P<0.05$

** Significant at $P \leq 0.001$

a Expenditures were calculated with marginal estimates from multivariable linear regression models adjusted for mother's age at child's birth; mother's race/ethnicity; mother's highest educational level achieved; mother's marital status; mother's county of residence; gestation weeks at birth; infant's birth weight; Healthy Start Screen score; HEDIS timely initiation of prenatal care [23]; HEDIS receipt of postpartum care [23]; Mother Chronic Illness and Disability Payment System health score [25]; and number of pregnancy complications

$\mathrm{b}$ Difference is the difference in costs among care coordination participants compared to women not receiving Healthy Start services. A positive difference indicates higher costs among the care coordination group and a negative difference indicates lower costs among the care coordination group

${ }^{c}$ Prenatal visits were identified using HEDIS definition of valid prenatal codes

${ }^{d}$ Early prenatal care is care during the first trimester or first 42 days of enrollment in Medicaid

\section{Infant Medical Expenditures}

Prior to the waiver, infant medical cost differences between the care coordination and no contact group were small (\$1.38-\$46.18), and not statistically significant. After the waiver, infant medical costs were higher among care coordination group compared to no contact group (Table 4); average costs were \$73.84-\$88.08 higher during days 2-28, and \$216.75-\$286.61 higher during days 29-365. From the pre-waiver to the late post-waiver, infant expenditures during days 2-28 decreased among the no contact group (\$70.87) and remained relatively stable in the care coordination group. The difference of these changes resulted in increased cost by the post-waiver when comparing the care coordination and the no contact groups (\$86.70).

Compared to the pre-waiver, infant expenditures during days 29-365 within both groups increased by the early post-waiver and decreased by the late post-waiver periods. Yet, average cost changes from pre-waiver to late post-waiver indicated cost savings among no contact group compared to the care coordination group (Table 4).

\section{Perinatal Care Medical Expenditures}

To summarize the influence of the 2001 Medicaid waiver on adjusted average perinatal medical expenditures, we compiled waiver differences for each mutually exclusive category of expenses. Specifically, for prenatal and postpartum care costs, we selected only all medical expenditures because these are comprehensive measures. From the pre-waiver to early-post waiver periods, care coordination participants had increased cost differences compared to non-contacted women for prenatal period care $(\$ 925)$, postpartum period care (\$73), and infant costs (2-28 days: $\$ 72$ and 29-365 days: \$170). Yet, compared to the no contact group, the women receiving care coordination had a costs savings of $\$ 182$ in delivery costs by the pre-waiver period. Similarly, from the pre-waiver to late-post waiver periods, care coordination participants had increased cost differences compared to non-contacted women for prenatal period care (\$875) and infant costs (2-28 days: $\$ 87$ and 29-365 days: $\$ 240$ ). The women receiving care coordination had a costs savings of $\$ 11$ in postpartum period care, and $\$ 395$ in delivery costs compared to the no contact group by the late post-waiver period. 
Table 3 Adjusted ${ }^{a}$ average delivery and postpartum care period expenditures and Differences between intervention and comparison groups by waiver period

\begin{tabular}{|c|c|c|c|c|c|}
\hline & $\begin{array}{l}\text { Pre-waiver } \\
\text { (Jan. 1, 1998- } \\
\text { July 1, 2001) }\end{array}$ & $\begin{array}{l}\text { Early post-waiver } \\
\text { (March 24, 2002- } \\
\text { July 1, 2004) }\end{array}$ & $\begin{array}{l}\text { Late post-waiver } \\
\text { (July 2, 2004- } \\
\text { December 31, 2006) }\end{array}$ & $\begin{array}{l}\text { Difference Early-post } \\
\text { waiver minus } \\
\text { pre-waiver }\end{array}$ & $\begin{array}{l}\text { Difference Late-post } \\
\text { waiver minus } \\
\text { pre-waiver }\end{array}$ \\
\hline \multicolumn{6}{|l|}{ Delivery } \\
\hline Care coordination & $\$ 4,681.42$ & $\$ 4,944.76$ & $\$ 5,002.84$ & $\$ 263.34 * *$ & $\$ 321.43 * *$ \\
\hline No contact & $\$ 4,775.29$ & $\$ 5,220.96$ & $\$ 5,491.71$ & $\$ 445.67 * *$ & $\$ 716.41 * *$ \\
\hline Difference $^{\mathrm{b}}$ & $-\$ 93.88^{*}$ & $-\$ 276.20^{*}$ & $-\$ 488.86 * *$ & $-\$ 182.33^{*}$ & $-\$ 394.98 * *$ \\
\hline \multicolumn{6}{|c|}{ All medical—postpartum } \\
\hline Care coordination & $\$ 3,207.72$ & $\$ 3,012.46$ & $\$ 3,132.54$ & $-\$ 195.26 * *$ & $-\$ 75.17$ \\
\hline No contact & $\$ 3,292.30$ & $\$ 3,023.93$ & $\$ 3,228.62$ & $-\$ 268.37 * *$ & $-\$ 63.68$ \\
\hline Difference & $-\$ 84.58 *$ & $-\$ 11.47$ & $-\$ 96.07$ & $\$ 73.11$ & $-\$ 11.49$ \\
\hline \multicolumn{6}{|l|}{ Postpartum visits ${ }^{\mathrm{c}}$} \\
\hline Care coordination & $\$ 968.36$ & $\$ 1,107.13$ & $\$ 1,182.89$ & $\$ 138.77 * *$ & $\$ 214.54 * *$ \\
\hline No contact & $\$ 1,009.95$ & $\$ 1,125.48$ & $\$ 1,212.01$ & $\$ 115.54 * *$ & $\$ 202.06 * *$ \\
\hline Difference & $-\$ 41.60 *$ & $-\$ 18.35$ & $-\$ 29.12$ & $\$ 23.25$ & $\$ 12.48$ \\
\hline
\end{tabular}

* Significant at $P<0.05$

** Significant at $P \leq 0.001$

${ }^{a}$ Expenditures were calculated with marginal estimates from multivariable linear regression models adjusted for mother's age at child's birth; mother's race/ethnicity; mother's highest educational level achieved; mother's marital status; mother's county of residence; gestation weeks at birth; infant's birth weight; Healthy Start Screen score; HEDIS timely initiation of prenatal care [23]; HEDIS receipt of postpartum care [23]; Mother Chronic Illness and Disability Payment System health score [25]; and number of pregnancy complications

${ }^{\mathrm{b}}$ Difference is the difference in costs among care coordination participants compared to women not receiving Healthy Start services. A positive difference indicates higher costs among the care coordination group and a negative difference indicates lower costs among the care coordination group

${ }^{c}$ Postpartum visits were identified using HEDIS definition of valid postpartum codes

\section{Conclusions}

Among Florida Medicaid non-MCO participants, the 2001 Florida Medicaid waiver is associated with an average $\$ 395$ delivery cost savings among the Healthy Start care coordination participants compared to women not contacted by the Healthy Start program. These delivery cost savings are offset, however, by increased costs following the waiver among care coordination compared to the no contact group for medical care during the prenatal period (\$875) and first year of life (\$327). While the observed program was not cost neutral, identifying factors related to the delivery cost savings may aid development of effective and efficient prenatal care programs.

The potential delivery cost saving found following the Florida Medicaid waiver is consistent with and expands understanding of case management based prenatal care [17, 18]. For example, among North Carolina Medicaid enrollees between 1988 and 1989, care coordination was associated with a $\$ 277$ cost savings in infant medical care during the first 60 days of life [17]. Because costs are substantially higher among newborns with medical problems than without medical problems [27], our findings of delivery cost savings are also consistent with the reduced number of poor birth outcomes observed among Florida
Healthy Start participants compared to non-participants in Hillsborough County [16]. Yet, the delivery cost savings may be caused by other factors, such as fewer Cesarean deliveries or shorter than recommended length of maternal hospital stays [24, 28, 29].

Our study adds to the mixed literature on whether moderate delivery cost savings compensate for additional costs of prenatal care $[17,30]$. Similar to another care coordination study [17], when we consider only HEDIS prenatal visits, the average delivery costs savings $(\$ 395)$ outweigh the additional average cost increases for prenatal visits $(\$ 100)$. Yet, similar to findings from an expanded prenatal care program [30], the increase in all prenatal medical costs in the care coordination group following the waiver (\$875) outweigh the delivery-related cost savings. Additionally, our results expand understanding of the influence of case management programs on infant costs beyond 60 days to the first full year of life $[17,18]$. Consistent with the lack of reduction of poor birth outcomes in other Healthy Start programs [12, 13], the potential cost benefits seen at delivery disappear by the end of the first year.

Our total average perinatal expenditure estimates range from $\$ 8,086$ to $\$ 8,700$ (found by summing the costs of all prenatal visits, all postpartum visits, delivery, and infant 
Table 4 Adjusted $^{\mathrm{a}}$ average infant all medical expenditures and differences between intervention and comparison groups by waiver period

\begin{tabular}{|c|c|c|c|c|c|}
\hline & $\begin{array}{l}\text { Pre-waiver } \\
\text { (Jan. 1, 1998- } \\
\text { July 1, 2001) }\end{array}$ & $\begin{array}{l}\text { Early post-waiver } \\
\text { (March 24, 2002- } \\
\text { July 1, 2004) }\end{array}$ & $\begin{array}{l}\text { Late post-waiver } \\
\text { (July 2, 2004- } \\
\text { December 31, 2006) }\end{array}$ & $\begin{array}{l}\text { Difference early-post } \\
\text { waiver minus } \\
\text { pre-waiver }\end{array}$ & $\begin{array}{l}\text { Difference late-post } \\
\text { waiver minus } \\
\text { pre-waiver }\end{array}$ \\
\hline \multicolumn{6}{|l|}{ 2-28 days } \\
\hline Care coordination & $\$ 951.17$ & $\$ 1,066.78$ & $\$ 967.00$ & $\$ 115.60 * *$ & $\$ 15.83$ \\
\hline No contact & $\$ 949.79$ & $\$ 992.93$ & $\$ 878.92$ & $\$ 43.14$ & $-\$ 70.87 *$ \\
\hline Difference $^{\mathrm{b}}$ & $\$ 1.38$ & $\$ 73.84^{*}$ & $\$ 88.08^{* *}$ & $\$ 72.46$ & $\$ 86.70^{*}$ \\
\hline \multicolumn{6}{|l|}{ 29-365 days } \\
\hline Care coordination & $\$ 3,161.32$ & $\$ 3,614.16$ & $\$ 2,732.18$ & $\$ 452.85 * *$ & $-\$ 429.13 * *$ \\
\hline No contact & $\$ 3,115.14$ & $\$ 3,397.42$ & $\$ 2,445.57$ & $\$ 282.28 *$ & $-\$ 669.57 * *$ \\
\hline Difference & $\$ 46.18$ & $\$ 216.75^{*}$ & $\$ 286.61 * *$ & $\$ 170.57$ & $\$ 240.43 * *$ \\
\hline
\end{tabular}

* Significant at $P<0.05$

** Significant at $P \leq 0.001$

${ }^{a}$ Expenditures were calculated with marginal estimates from multivariable linear regression models adjusted for mother's age at child's birth; mother's race/ethnicity; mother's highest educational level achieved; mother's marital status; mother's county of residence; gestation weeks at birth; infant's birth weight; Healthy Start Screen score; HEDIS timely initiation of prenatal care [23]; HEDIS receipt of postpartum care [23]; Mother Chronic Illness and Disability Payment System health score [25]; and number of pregnancy complications

${ }^{b}$ Difference is the difference in costs among care coordination participants compared to women not receiving Healthy Start services. A positive difference indicates higher costs among the care coordination group and a negative difference indicates lower costs among the care coordination group

care between 2-28 days within each time period), and are similar to the $\$ 8,821$ (converted to 2008 dollars [8]) previously estimated among Florida Medicaid enrollees [31]. This comparison suggests consistency, despite methodological differences and slightly different populations (e.g., we restricted to births from women with screen scores of $\geq 4$ ).

There are four important limitations to this study. First, despite adjusting our analysis for several covariates, confounding by unmeasured covariates (e.g., social support) remains a possibility because a temporal comparison group was not available. Second, our results may not generalize to Florida Medicaid non-MCO enrollees, Healthy Start participants, or Medicaid MCO enrollees because of missing data, and our prioritizing internal over external validity. Our results represent singleton births to women who were: (1) at increased risk of poor birth outcomes (Healthy Start screen score of $\geq 4$ ); (2) enrolled in Florida Medicaid non-MCO programs (not due to medical need); (3) had linkable Healthy Start, birth, and Medicaid data; and (4) received care coordination or were not contacted for participation in the Healthy Start program. Third, we were unable to assess potential long-term medical cost benefits to the mother or the child from the additional services provided to care coordination participants. For example, women receiving smoking cessation counseling may reduce their child's long-term risk of asthma. Fourth, implementation of the Florida Healthy Start program likely differs across the state because several community-based coalitions coordinate the program. By combining the coalitions into a statewide program, we may have masked positive effects of extraordinary programs.

There were three important strengths of this study. First, the large statewide study population $(n=65,349)$ allowed us to adjust the analysis for tweleve important covariates. Second, recall bias for perinatal expenditures was reduced because we used Medicaid paid claims that are reported independently of Healthy Start program. Third, expenditures and covariates were available for 3 years prior to the Medicaid waiver and 6 years after the waiver, enabling us to evaluate short- and long-term waiver effects.

Our study supports the potential cost benefit of care coordination programs like Florida Healthy Start by showing reduced delivery costs following program expansion. The increased costs of prenatal and infant care, however, suggest additional research is needed to isolate specific services or exemplary program sites responsible for the reduced delivery costs. Increased understanding of the factors driving the observed delivery cost savings may allow development of more effective and efficient prenatal care programs.

Acknowledgments The research was supported in part by funding from the Florida Agency for Health Care Administration. The authors wish to thank Cheryl L. Clark, DrPH, RHIA and Marie Melton from the Florida Department of Health for useful conversations regarding Healthy Start operations. We also thank Charmy Chhichhia, J. Roger Clemmons, and Briony Tatem, MS from the Institute for Child Health Policy for data management and technical assistance. Publication of this article was funded in part by the University of Florida OpenAccess Publishing Fund. 
Open Access This article is distributed under the terms of the Creative Commons Attribution Noncommercial License which permits any noncommercial use, distribution, and reproduction in any medium, provided the original author(s) and source are credited.

\section{References}

1. Martin, J. A., Hamilton, B. E., Sutton, P. D., Ventura, S. J., Menacker, F., Kirmeyer, S., et al. (2009). Births: Final data for 2006. Hyattsville, MD: National Center for Health Statistics, US Department of Health \& Human Services.

2. Tomashek, K. M., Shapiro-Mendoza, C. K., Davidoff, M. J., \& Petrini, J. R. (2007). Differences in mortality between late-preterm and term singleton infants in the United States, 1995-2002. Journal of Pediatrics, 151(5), 450-456, 456eI.

3. Shapiro-Mendoza, C. K., Tomashek, K. M., Kotelchuck, M., Barfield, W., Nannini, A., Weiss, J., et al. (2008). Effect of latepreterm birth and maternal medical conditions on newborn morbidity risk. Pediatrics, 121(2), e223-e232.

4. Underwood, M. A., Danielsen, B., \& Gilbert, W. M. (2007). Cost, causes and rates of rehospitalization of preterm infants. Journal of Perinatology, 27(10), 614-619.

5. Swamy, G. K., Ostbye, T., \& Skjaerven, R. (2008). Association of preterm birth with long-term survival, reproduction, and nextgeneration preterm birth. Journal of the American Medical Association, 299(12), 1429-1436.

6. Hack, M., Klein, N. K., \& Taylor, H. G. (1995). Long-term developmental outcomes of low birth weight infants. Future of Children Journal, 5(1), 176-196.

7. Fanaroff, A. A., Stoll, B. J., Wright, L. L., Carlo, W. A., Ehrenkranz, R. A., \& Stark, A. R., et al. (2007). Trends in neonatal morbidity and mortality for very low birthweight infants. American Journal of Obstetrics \& Gynecology, 196(2), 147.e1-147.e8.

8. Bureau of Labor Statistics. (2010). Consumer price index summary. Division of Consumer Prices and Price Indexes. Available at: http://www.bls.gov/news.release/cpi.nr0.htm. Accessed 11 April 2011.

9. Behrman, R. E., \& Butler, A. S. (Eds.). (2007). Preterm birth: Causes, consequences, and prevention. Washington, D.C.: The National Academies Press. Committee on Understanding Premature Birth and Assuring Healthy Outcomes: Board on Health Sciences Policy. Institute of Medicine of the Academies.

10. Lewit, E. M., Baker, L. S., Corman, H., \& Shiono, P. H. (1995). The direct cost of low birth weight. Future of Children Journal, 5(1), 35-56

11. Howell, E. M., Devaney, B., McCormick, M., \& Raykovich, K. T. (1998). Back to the future: Community involvement in the healthy start program. Journal of Health Politics, Policy and Law, 23(2), 291-317.

12. McCormick, M. C., Deal, L. W., Devaney, B. L., Chu, D., Moreno, L., \& Raykovich, K. T. (2001). The impact on clients of a community-based infant mortality reduction program: The National Healthy Start Program Survey of Postpartum Women. American Journal of Public Health, 91(12), 1975-1977.

13. Reichman, N. E., \& Teitler, J. O. (2003). Effects of psychosocial risk factors and prenatal interventions on birth weight: evidence from New Jersey's Health Start program. Perspectives on Sexual and Reproductive Health, 35(3), 130-137.
14. Haas, J. S., Udvarhelyi, I. S., Morris, C. N., \& Epstein, A. M. (1993). The effect of providing health coverage to poor uninsured pregnant women in Massachusetts. Journal of the American Medical Association, 269(1), 87-91.

15. Piper, J. M., Mitchel, E. F., Jr, \& Ray, W. A. (1996). Evaluation of a program for prenatal care case management. Family Planning Perspectives, 28(2), 65-68.

16. Salihu, H. M., Mbah, A. K., Jeffers, D., Alio, A. P., \& Berry, L. (2009). Healthy start program and feto-infant morbidity outcomes: evaluation of program effectiveness. Maternal and Child Health Journal, 13(1), 56-65.

17. Buescher, P. A., Roth, M. S., Williams, D., \& Goforth, C. M. (1991). An evaluation of the impact of maternity care coordination on Medicaid birth outcomes in North Carolina. American Journal of Public Health, 81(12), 1625-1629.

18. Cramer, M. E., Chen, L. W., Roberts, S., \& Clute, D. (2007). Evaluating the social and economic impact of community-based prenatal care. Public Health Nursing, 24(4), 329-336.

19. Mackey, M. C., \& Alexander, F. W. (2003). Program management of high-risk pregnancy-outcomes and costs. Disease Management \& Health Outcomes, 11(1), 1-6.

20. Florida Department of Health. (2009). Healthy start annual report, 2008. Florida Department of Health. 2 January, 2009.

21. Florida Department of Health. (2009). Florida's healthy start. Available at: http://www.doh.state.fl.us/family/mch/hs/hs.html. Accessed 11 April 2011.

22. Florida Department of Health. (2009). 2007 Healthy start standards and guidelines. Available at: http://www.doh.state.fl.us/ family/mch/hs/hstraining/hstraining.html. Accessed 11 April 2011.

23. National Commission on Quality Assurance. (2008). HEDIS technical specifications, Vol. 2. Available at: http://www.ncqa. org/tabid/78/Default.aspx\#HEDISMD. Accessed 11 April 2011.

24. Howell, E. M., \& Brown, G. A. (1989). Prenatal, delivery, and infant care under Medicaid in three states. Health Care Finance Review, 10(4), 1-15.

25. Kronick, R., Gilmer, T., Dreyfus, T., \& Lee, L. (2000). Improving health-based payment for Medicaid beneficiaries: CDPS. Health Care Finance Review, 21(3), 29-64.

26. Duan, N. (1983). Smearing estimate: A nonparametric retransformation method. Journal of the American Statistical Association, 78(383), 605-610.

27. Russell, R. B., Green, N. S., Steiner, C. A., Meikle, S., Howse, J. L., Poschman, K., et al. (2007). Cost of hospitalization for preterm and low birth weight infants in the United States. Pediatrics, 120(1), e1-e9.

28. Tai-Seale, M., LoSasso, A. T., Freund, D. A., \& Gerber, S. E. (2001). The long-term effects of Medicaid managed care on obstetrics care in three California counties. Health Services Research, 36(4), 751-771.

29. Tai-Seale, M., Rodwin, M., \& Wedig, G. (1999). Drive-through delivery: Where are the "savings"? Medical Care Research and Review, 56(1), 30-46.

30. Joyce, T. (1999). Impact of augmented prenatal care on birth outcomes of Medicaid recipients in New York City. Journal of Health Economics, 18(1), 31-67.

31. Kenney, A. M., Torres, A., Dittes, N., \& Macias, J. (1986). Medicaid expenditures for maternity and newborn care in America. Family Planning Perspectives, 18(3), 103-110. 